\title{
The Stereoselective Formation of Bicyclic Enamines with Bridgehead Unsaturation via Tandem C-H Bond Activation/ Alkenylation/Electrocyclization
}

\author{
Sirilata Yotphan, Robert G. Bergman, and Jonathan A. Ellman \\ Department of Chemistry, University of California, and Division of Chemical Sciences, Lawrence \\ Berkeley National Laboratory, Berkeley, California 94720
}

\begin{abstract}

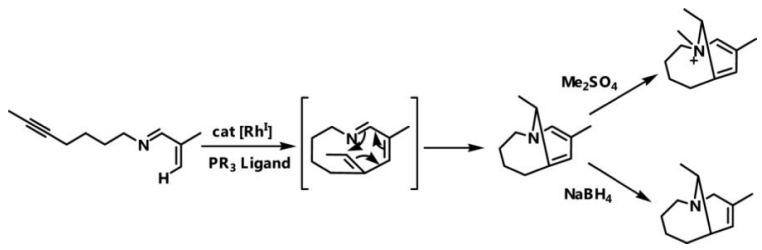

Bridgehead bicyclic unsaturated enamines were prepared by a tandem rhodium-catalyzed $\mathrm{C}-\mathrm{H}$ bond activation/alkenylation/electrocyclization of alkyne-tethered unsaturated imines. These strained bicyclic enamines exhibit unique reactivity: for example, they give $N$-Alkylated products upon treatment with alkylating reagents and undergo double bond isomerization to alleviate ring strain upon reduction.
\end{abstract}

Rhodium-catalyzed intermolecular $\mathrm{C}-\mathrm{H}$ activation of $\alpha, \beta$-unsaturated imines in the presence of alkynes leads to a tandem process in which coupling to the alkyne occurs at the $\beta-\mathrm{C}-\mathrm{H}$ bond of the imine, followed by electrocyclization of the resulting azatriene intermediates to give dihydropyridines (eq 1). ${ }^{1,2}$

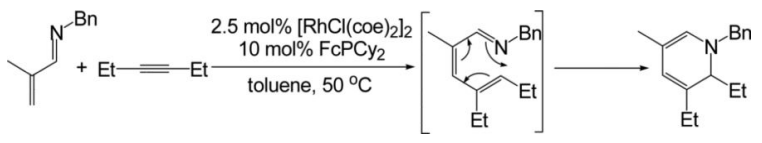

Consideration of the intramolecular version of this overall transformation (Scheme 1) raises interesting regiochemical issues. For example in a compound such as $\mathbf{1}$, where the nitrogen and alkyne are connected by a 4-carbon tether, the presumed first-formed hydrido(vinyl)rhodium function can add to the triple bond in a 1,2-fashion, producing complex 2 with a new endocyclic double bond. Alternatively, addition might occur in a 2,1fashion, leading to product $\mathbf{4}$ with an exocyclic double bond.

We now wish to report that this intramolecular cyclization occurs smoothly at $100{ }^{\circ} \mathrm{C}$, and the exocyclic double bond route is exclusively followed. Remarkably, products such as $\mathbf{4}$ do

bergman@cchem.berkeley.edu; jellman@uclink.berkeley.edu.

Supporting Information Available: Complete experimental details and spectral data for all compounds described (PDF, CIF). This material is available free of charge via the Internet at http://pubs.acs.org. 
not resist further cyclization. Even though both the transition state for this process and the resulting product are presumably strained, the overall transformation leads to good yields of unusual bridgehead doubly-bonded enamines such as $5 .{ }^{3}$ The unique chemistry of conjugated enamine $\mathbf{5}$ is consistent with the increased strain of this molecule as well as with inhibited conjugation between the nitrogen lone pair and the adjacent double bond (vida infra).

We began our investigation into the $\mathrm{C}-\mathrm{H}$ activation/cyclization of alkyne-tethered imine $\mathbf{1}$ by extensive screening of transition metal catalysts for this process. ${ }^{4}$ Rhodium-based catalysts were found to be the most efficient (Table 1), leading exclusively to the bridgehead dienamine; none of the catalysts that were employed in the screening led to quinolizidine 3 or to the product of intramolecular Diels-Alder reaction.

The optimized reaction conditions employ the electron-rich monophosphine ligand ( $p$ $\mathrm{NMe}_{2}$ ) $\mathrm{PhPEt}_{2}$ in 1:1 ratio relative to the metal (entry 6). ${ }^{1 \mathrm{~b}}$ Other phosphine ligands also provided product 5 , but lower yields were observed. Of particular note, the commercially available phosphine, $\mathrm{PCy}_{3}$, gave yields that were nearly identical to those obtained using the optimized conditions (entry 4). Monitoring the progress of the reaction by NMR showed that the nine-membered ring aza-triene intermediate $\mathbf{4}$ was observed to form initially, as is proposed in Scheme 1. This intermediate undergoes spontaneous thermal electrocyclization to form $5 .{ }^{5}$ In the Rh-H addition step, the geometry of the alkynetethered imine substrate presumably guides $\mathrm{H}$-transfer to the less hindered site of the tethered alkyne.

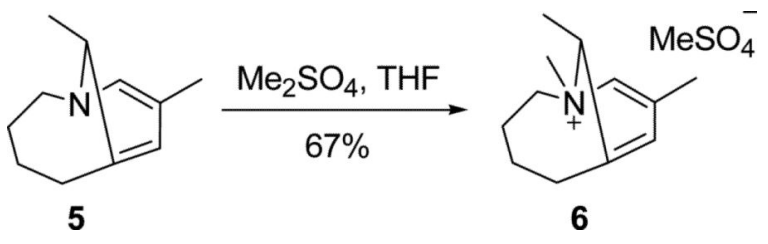

We also investigated the chemistry of $\mathbf{5}$ due to its novel structure. Upon treatment with $\mathrm{Me}_{2} \mathrm{SO}_{4}, \mathbf{5}$ was converted exclusively to $\mathrm{N}$-methylated product $\mathbf{6}$, a regioselectivity that is opposite to that observed with acyclic and monocyclic enamines, which usually give $C$ alkylation (eq 2) ${ }^{6,7}$ Crystals of $\mathbf{6}$ suitable for X-ray analysis were obtained, and the resulting crystal structure (Figure 1) confirmed the structure for $\mathbf{5}$ proposed above. The bridgehead double bond of $\mathbf{6}$ is found to be significantly non-planar (twist). ${ }^{8}$ The deviation from the optimal planar geometry caused by the bicyclic structure in $\mathbf{5}$ presumably also results in poor delocalization of the nitrogen lone pair electrons into the adjacent diene orbitals, which would account for the observation of $N$-alkylation. ${ }^{9}$

Hydrogenation of $\mathbf{5}$ under standard conditions gives the fully reduced tertiary amine product 7 as a single diastereomer (eq 3). Ring strain is also alleviated by reduction of 5 with $\mathrm{NaBH}_{4}$ in methanol, which provides $\mathbf{8}$ as the only product (eq 4). This result contrasts with the reduction of 1,2-dihydropyridines under the same conditions, which proceeds without overall double bond isomerization. ${ }^{10}$

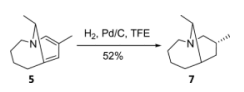




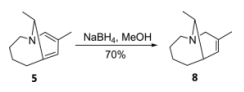

To investigate the mechanism of the borohydride reduction, two isotope labeling studies were conducted. Reduction of $\mathbf{5}$ with $\mathrm{NaBH}_{4}$ in MeOD- $d_{4}$ results in the placement of a deuterium at the bridgehead (eq 5), while treatment of 5 with $\mathrm{NaBD}_{4}$ in $\mathrm{MeOH}$ results in product that is deuterated at the position $\alpha$ to nitrogen (eq 6). Based on these observations, we propose that the overall reaction involves initial reversible protonation by $\mathrm{MeOH}$ to give iminium intermediate 11, and followed by hydride attack on the strained iminium double bond (Scheme 2b).

Other $\alpha, \beta$-unsaturated aldimine substrates with tethered alkynyl groups were also examined. Imine 12 with a tether shorter than $\mathbf{1}$ undergoes $\mathrm{C}-\mathrm{H}$ functionalization to form a smaller eight-membered ring aza-triene intermediate 13 (detectable by NMR). However, this unstable species decomposes over time and the bicyclic product analogous to $\mathbf{5}$ was not detected (eq 7). It is likely that the optimum geometry required for cyclization in the eightmembered ring cannot be achieved.

Imine 14 with a methyl group $\alpha$ to the nitrogen provides bridgehead nine-membered ring 15 as a single diastereomer (eq 8). The prolonged reaction time was necessary due to a slow electrocyclization step. We also investigated the reaction of substrate 16, but the expected bridgehead product was not obtained. Instead, bicyclic amine 17 with an exocyclic double bond was formed (eq 9). This product is likely formed by isomerization to relieve ring strain. However, a lower yield was obtained in the case of the more highly substituted imine 18.

In summary, we have demonstrated the Rh-catalyzed $\mathrm{C}-\mathrm{H}$ activation of alkyne-tethered $\alpha, \beta$ unsaturated imines, followed by reaction of the activated intermediate with alkynes. This leads to an intermediate that undergoes further spontaneous thermal electrocyclization to form strained bicyclic enamines with bridgehead unsaturation. The unique chemistry of these products in alkylation and reduction is a consequence of the strain in the bicyclic system.

\section{Supplementary Material}

Refer to Web version on PubMed Central for supplementary material.

\section{Acknowledgments}

This work was supported by the NIH Grant GM069559 to J.A.E. and the Director and Office of Energy Research, Office of Basic Energy Sciences, Chemical Sciences Division, U.S. Department of Energy, under Contract DEAC03-76SF00098 to R.G.B. We thank Denise A. Colby for phosphine ligands and Dr. Frederick J. Hollander and Geza Szigethy of the Berkeley CHEXray facility for solving the X-ray crystal structure of $\mathbf{6}$.

\section{References}

1. a Colby DA, Bergman RG, Ellman JA. J. Am. Chem. Soc. 2006; 128:5604. [PubMed: 16637605] b Colby DA, Bergman RG, Ellman JA. J. Am. Chem. Soc. 2008 In press.

2. Cao C, Li Y, Shi Y, Odom AL. Chem. Commun. 2004:2002.

3. For analogous bridgehead bicyclic amides and enamines see: a Kirby AJ, Komarov IV, Feeder N. J. Chem. Soc., Perkin Trans. 2001; 2:522. b Lease TG, Shea KJ. J. Am. Chem. Soc. 1993; 115:2248. c Sparks SM, Chow CP, Zhu L, Shea KJ. J. Org. Chem. 2004; 69:3025. [PubMed: 15104440] d Tani 
K, Stoltz BM. Nature. 2006; 441:731. [PubMed: 16760973] e Yao L, Aubé J. J. Am. Chem. Soc. 2007; 129:2766. [PubMed: 17302421]

4. See supporting information for experimental procedures for the preparation and cyclization of alkyne-tethered imine substrates.

5. Aza-triene intermediate either results in decomposition or undergoes spontaneous electrocyclization to give bridgehead product upon isolation. Therefore, we are unable to determine whether electrocyclization is catalyzed by $\mathrm{Rh}$, proton or Lewis acid.

6. Other methylating agents such as MeI also give N-methylation.

7. Cook, AG. Enamines: Synthesis, Structure and Reaction. Marcel Dekker Inc.; New York-London: 1988. p. 181-204.

8. Torsional angle $=146.2^{\circ}$ (see CIF file for more detail).

9. A similar $N$-methylation of the twisted bridgehead enamine has been reported in ref $3 \mathrm{a}$.

10. For the reduction of 1,2-dihydropyridines with $\mathrm{NaBH}_{4}$ in $\mathrm{MeOH}$ without double bond isomerization see: a Casini A, Di Rienzo B, Micheletti Moracci F, Tortorella S, Liberatore F. Tett. Lett. 1978; 24:2139. b Jacobson AE, May EL. J. Med. Chem. 1964; 7:409. [PubMed: 14221116] c Jacobson AE, May EJ. J. Med. Chem. 1965; 8:563. d Hori M, Ban M, Imai E, Iwata N, Suzuki Y, Baba Y, Morita T, Fujiyama H, Nozaki M, Niwa M. J. Med. Chem. 1985; 28:1656. [PubMed: 2999399]

11. Yields were calculated by NMR integration relative to internal standard (see supporting information for isolated yields). 


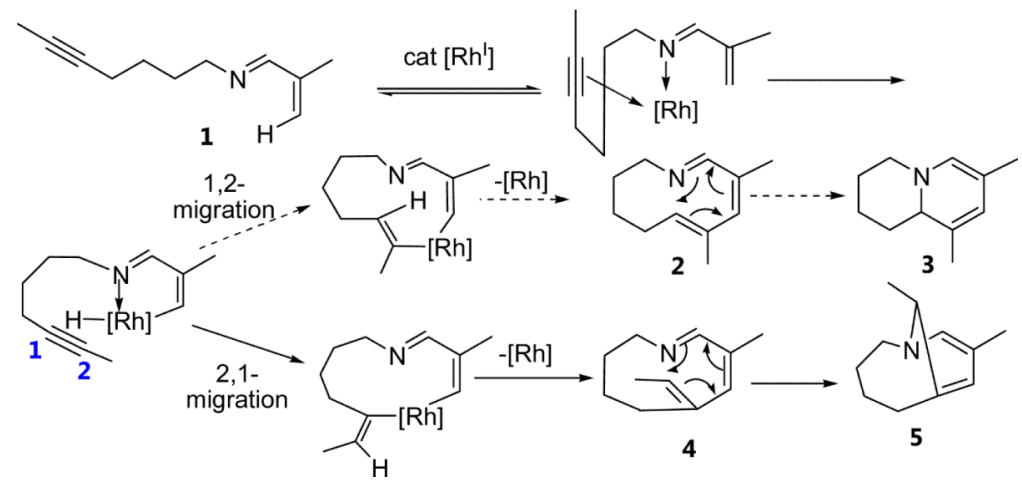

Scheme 1.

Proposed Mechanism for the Formation of $\mathbf{5}$. 


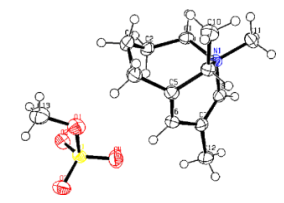

Figure 1.

ORTEP diagram with $50 \%$ thermal ellipsoids illustrating the results of the X-Ray crystal structure determination of $\mathbf{6}$. 


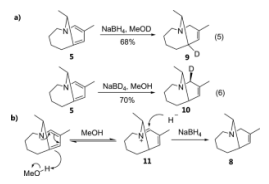

Scheme 2.

a) Isotope labeling experiments of $\mathrm{NaBH}_{4}$ reduction

b) The proposed mechanism of $\mathrm{NaBH}_{4}$ reduction 


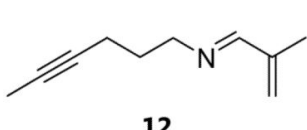

$2.5 \mathrm{~mol} \%\left[\mathrm{RhCl}(\mathrm{COe})_{2}\right]_{2}$ $5.0 \mathrm{~mol} \%\left(p-\mathrm{NMe}_{2}\right) \mathrm{PhPEt}_{2}$ toluene, $100^{\circ} \mathrm{C}, 3 \mathrm{~h}$

12

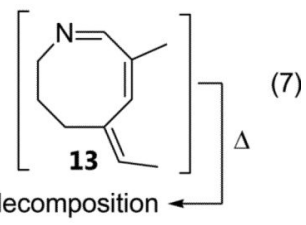

(7)

decomposition
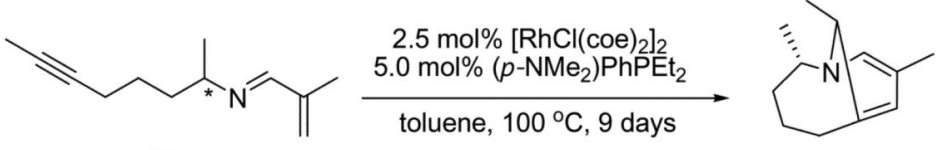

14

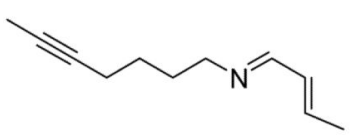

$15(63 \%)$

16
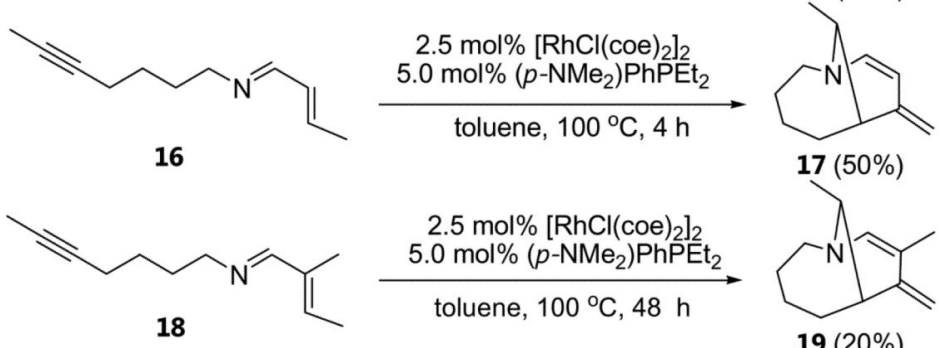

$17(50 \%)$

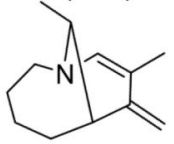

$19(20 \%)$

Scheme 3.

C-H Functionalization of other imine substrates. ${ }^{11}$ 
Table 1

Optimization of Reaction Conditions

\begin{tabular}{|c|c|c|c|c|}
\hline & 1 & $\begin{array}{c}5 \text { mol } \% \text { cataly } \\
\text { toluene } \\
100^{\circ} \mathrm{C}\end{array}$ & & 5 \\
\hline Entry & Catalyst & Added Ligand $a$ & time (h) & $\%$ Yield $^{b}$ \\
\hline 1 & $\mathrm{Ru}\left(\mathrm{H}_{2}\right) \mathrm{CO}\left(\mathrm{PPh}_{3}\right)_{3}$ & - & 4 & 45 \\
\hline 2 & $\mathrm{Rh}\left(\mathrm{PPh}_{3}\right)_{3} \mathrm{Cl}$ & - & 4 & 59 \\
\hline 3 & {$\left[\mathrm{Rh}(\operatorname{coe})_{2} \mathrm{Cl}\right]_{2}$} & $\mathrm{PPh}_{3}$ & 2 & 41 \\
\hline 4 & {$\left[\mathrm{Rh}(\mathrm{coe})_{2} \mathrm{Cl}\right]_{2}$} & $\mathrm{PCy}_{3}$ & 8 & 72 \\
\hline 5 & {$\left[\mathrm{Rh}(\text { coe })_{2} \mathrm{Cl}\right]_{2}$} & $\mathrm{FcPCy}_{2}$ & 4 & 52 \\
\hline 6 & {$\left[\mathrm{Rh}(\operatorname{coe})_{2} \mathrm{Cl}\right]_{2}$} & $\left(p-\mathrm{NMe}_{2}\right) \mathrm{PhPEt}_{2}$ & 4 & $75(54) c$ \\
\hline 7 & {$\left[\mathrm{Rh}(\mathrm{coe})_{2} \mathrm{Cl}\right]_{2}$} & $\left(p-\mathrm{NMe}_{2}\right) \mathrm{PhPCy}_{2}$ & 4 & 72 \\
\hline
\end{tabular}

$a_{5 \mathrm{~mol}} \%$ ligand (1:1 ratio to the catalyst) was added.

${ }^{b}$ All yields were determined by NMR integration relative to 2,6-dimethoxytoluene as an internal standard.

${ }^{c}$ Isolated yield. 